\title{
濒危植物明党参与非濒危种峨参种子 休眠和萌发比较
}

\section{殷现伟 常 杰 葛 㳥 关保华 樊梅英 邱英雄}

( 浙江大学生命科学学院, 杭州 310029)

摘要: 研究了濒危植物明党参 (Changium smyrnioides) 与非濒危种峨参 (Anthriscus sylvestris) 种子諚存、打破休眠和 萌发对水分和温度条件的要求。结果表明, 在自然条件下, 明党参种子有 5 个月的休眠期, 人工低温 ( $10^{\circ} \mathrm{C}$ 左右) 处 理 40 天即可打破休眠; 两种植物种子自然温度干燥处理不能打破休眠; 两种植物的种子在自然温度变湿层积处理 后萌发率最高, 萌发持续时间也最长, 其中明党参的萌发率高于峨参, 持续时间短于峨参; 自然温度淹水处理大大 降低了两种植物种子的萌发率, 但明党参仍有 $7 \%$ 的萌发率。明党参种子质量和发芽率不应是明党参濒危的直接 原因, 但因其具有种子产量低、幼苗数量少、存活率高的 $K$-对策, 当受到强烈干扰时, 种群难以在短期内恢复, 容易 濒危。

关键词：咜藏条件, 水分, 温度,$K$-对策

中图分类号:Q945.6 ${ }^{+} 5$ 文献标识码 : A 文章编号 : 1005-0094(2002)04-0425-06

\section{A comparison of dormancy and germination of seeds between an endan- gered species, Changium smyrnioides, and a non - endangered species, Anthriscus sylvestris}

\author{
YIN Xian-Wei , CHANG Jie , GE Ying , GUAN Bao-Hua , FAN Mei-Ying , QIU Ying-Xiong \\ College of Life Science, Zhejiang University, Hangzhou 310029
}

Abstract : The dormancy and germination of seeds of an endangered species , Changium smyrnioides, and another non-endangered species, Anthriscus sylvestris, were studied under different storage conditions. The results showed that in natural condition, the seeds of $C$. smyrnioides had a dormancy stage for about five months, and that experimental low temperature ( about $10^{\circ} \mathrm{C}$ ) could break dormancy after 40 days of treatment. Seeds stored under natural temperature and dry condition could not break dormancy, while those stored under natural temperature and fluctuant moisture condition had the highest germination ratio , and their germination ability lasted for a longer time than any other treatments. The germination ratio of C. smyrnioides was higher than that of A. sylvestris, while the germination duration was shorter. Germination of seeds stored under natural temperature and saturated moisture conditions decreased markedly in both species, although in C. smyrnioides the germination could remain at $7 \%$. Apparently, the quality and germination ability of seeds of $C$. smyrnioides is not the direct reason for its endangerment. The species follows a $K$-strategy, with the characteristics of a big seed grain, lower seed production, and few seedlings created. As a result, the population cannot be restored quickly when disturbed intensively and the species has a greater possibility of endangerment.

Key words : storage condition, water, temperature , $K$-strategy 
植物濒危的原因除了人类过度利用及生境的破 坏外, 还有自身生物学方面的原因。对许多濒危植 物的研究发现, 种子质量差、萌发率低、被取食严重、 萌发所需的条件与其生境不协调等是造成其濒危的 重要原因(葛滢等,1998)。

明党参 (Changium smyrnioides) 是我国特有的金形 科明党参属的单种属植物，仅分布于我国浙江、安徽、 江苏、江西、河南等省，是名贵中药材之一。由于人类 挖掘和生境的破坏 其分布区和个体数量正日益减少， 近年来其种群呈现明显衰退倾向（邱英雄，傅承新， 2001 )，1984 年被列入国家三级濒危保护植物(国家环 保局,中国科学院植物研究所,1991)。邱英雄等 (2001) 认为, 当明党参种子从母体下落时适逢长江中 下游地区的梅雨季节，长期的浸水易造成胚的腐烂而 死亡。另有研究表明, 明党参种子在干燥条件下易失 去活力, 而且温度会影响到胚的发育(刘守炉, 叶锦生， 1991 王中否,刘兴剑,2000)。峨参 (Anthriscus sylvestris) 也是伞形科的一种药用植物，分布于我国亚热带、 温带省份以及欧洲和北美洲的温带地区,也被高强度 采挖作为药材, 但却没有表现出濒危趋势。峨参种子 与明党参种子几乎同时成熟, 并且也在冬季萌发生长, 但种群更新良好。因此梅雨季节看来并不一定会破坏 种子的发芽能力。那么 到底是什么生态因子影响了 明党参的种子活力? 又在多大程度上影响其萌发? 为 此，我们根据野外环境为明党参设计了不同的咜藏条 件,并以峨参为对照来研究不同咜藏条件对明党参种 子萌发的影响, 试图从种子生态学角度探讨其濒危的 机制,为迁地保护和人工繁殖利用提供依据。

\section{1 材料和方法}

\section{1 试验材料}

明党参种子呈圆形至卵状长圆形, 黑色, 侧面 扁, 光滑, 长 $3.95 \pm 0.47 \mathrm{~mm}$, 直径 $1.95 \pm 0.28 \mathrm{~mm}$ 。 峨参种子长卵形至线长圆形,黑色, 长 $5.45 \pm 0.21$ $\mathrm{mm}$, 直径 $1.15 \pm 0.18 \mathrm{~mm}$, 光滑或具小瘤点, 顶端渐 狭成喙状。明党参种子在 6 月中旬成熟,峨参在 6 月初成熟。两种植物种子在成熟下落后, 均不能立 即萌发, 而是进入休眠, 在自然条件下要到 11 月底 才开始萌发。

研究用明党参种子于 2000 年 6 月 19 日采自杭 州市南高峰, 峨参种子于同年 6 月 5 日采自杭州南 高峰和午潮山。种子采回后, 自然风干 15 天至稳定
含水量 (明党参和峨参分别为 $14.4 \%$ 和 $14.3 \%$ )。 为避免因种子质量差而影响试验结果(葛溁等, 1998 ;卢毅军等 2001)，用水选法将种子分成上下两 层, 再风干至水选前的稳定含水量, 测定上下层种子 千粒重、种子重量等数据。用明党参和峨参水选下 层种子分别于 2000 年 7 月 5 日和 19 日开始进行各 种试验处理, 由于上层种子数量少, 只进行了常温干 咜 到其他处理种子结束休眠时已经失去活力, 所以 2001 年又采集种子进行补充试验。

\section{2 水分处理}

在自然温度条件下将种子埋在沙中, 沙覆盖的 厚度为 $0.5 \sim 1.0 \mathrm{~cm}$, 对其进行 3 种水分处理:(1) 干燥层积处理。将种子埋在干沙 (含水量 1.7\%) 中; (2) 变湿层积处理。先将埋有种子的沙浇水至 饱和, 待表面 $1 \mathrm{~cm}$ 干燥时再浇水至饱和, 以模拟自 然间歇式降水; (3) 淹水层积处理。使沙始终处于 水分过饱和状态 (沙含水量 $>21.4 \%$ )，模拟自然水 边环境。每个处理 8 个重复,每个重复 50 粒种子。

\section{3 温度处理}

对进行干燥层积处理和变湿层积处理的明党参 和峨参种子, 除放置于自然温度下 (杭州地区 $6 \sim 12$ 月间极端高温 $38^{\circ} \mathrm{C}$, 极端低温 $\left.0^{\circ} \mathrm{C}\right)(\mathrm{Ge} \&$ Chang, $2001)$ 外, 还同时放置在低温 $\left(10^{\circ} \mathrm{C}\right.$ 左右) 条件下。 每个处理 8 个重复, 每个重复 50 粒种子。

\section{4 发芽方法和数据处理}

变湿处理和淹水处理的种子从采收开始就放置 在自然温度条件下 (萌发期内日平均气温 $6.5^{\circ} \mathrm{C} \sim$ $10.5^{\circ} \mathrm{C}$, 最低 $-3^{\circ} \mathrm{C}$, 最高 $18^{\circ} \mathrm{C}$ ), 直至萌发结束; 干 燥处理的种子也放置在自然温度下, 直至变湿处理 的种子开始萌发时, 意味着种子休眠结束, 此时再按 变湿处理方式加水开始萌发试验。自萌发的芽从沙 中开始露出起记录萌发数, 然后每 2 天观察记录一 次。萌发结束后计算萌发值 $(G V)$,用萌发值和萌发 持续天数来表示萌发速率 (Czabator，1962；Kainer et al. , 1999)。

$$
G V=M D G \times P V
$$

其中 , $M D G$ 为日平均萌发率, $M D G(\% / \mathrm{d})=G s / G d$, $G s$ 及 $G d$ 分别为总萌发率与总萌发天数; $P V$ 为峰 值, 是最大平均日萌发率, $P V=G p t / D p t, G p t$ 指达到 高峰日时的发芽量, Dpt 指达到高峰值的天数。萌 发持续时间为该物种自萌发开始至萌发结束所经历 的天数。 


\section{2 结果与分析}

\section{1 两种植物种子的生物学和生态学特性}

两种植物种子通过水选, 分为上下两层。明党 参上层种子所占比例较大, 为 $31.7 \%$,峨参上层种 子仅为 $4.4 \%$ 。两个种上层种子千粒重均小于下层 $(P<0.001)$ 。明党参下层种子的千粒重比上层高 $71.0 \%$,而峨参下层种子的千粒重仅比上层高 $24.5 \%$ 。同时, 明党参上、下层种子千粒重差别大于 峨参, 这意味着明党参种子质量差异较峨参大 (表 1)。两者上层种子的千粒重差别很小, 但明党参的

\section{下层种子千粒重明显大于峨参。}

\section{2 不同水分层积处理对种子萌发的影响}

在自然温度下,变湿及淹水层积处理的明党参 种子均于 12 月 23 日开始萌发, 经历了 158 天的休 眠期; 峨参则分别于 11 月 28 日和 12 月 6 日开始萌 发,分别经历了 146 天和 154 天的休眠期。这表明， 两种植物的种子在自然温度变湿及淹水层积后, 可 通过后熟而解除休眠萌发。干燥层积的种子在其他 贮藏条件种子休眠结束后也按变湿处理方式加水进 行萌发试验,但均没有萌发, 以后一直未再萌发, 表 明自然温度干燥处理不能打破种子休眠 (表 2 )。

表 1 明党参和峨参种子千粒重

Table 1 Kilo-grain weight of seeds of Changium smyrnioides and Anthriscus sylvestris

\begin{tabular}{ccccc}
$\begin{array}{c}\text { 种名 } \\
\text { Species }\end{array}$ & $\begin{array}{c}\text { 下层千粒重 } \\
\text { Kilo-grain weight } \\
\text { of lower layer } \\
\text { seeds }(\mathrm{g})\end{array}$ & $\begin{array}{c}\text { 上层千粒重 } \\
\text { Kilo-grain weight } \\
\text { of upper layer } \\
\text { seeds }(\mathrm{g})\end{array}$ & $\begin{array}{c}\text { 上下层种子差异显著性 } \\
\text { Significance of difference } \\
\text { between upper and lower } \\
\text { seeds }(P \text { value })\end{array}$ & $\begin{array}{c}\text { 上层种子比例 } \\
\text { Proportion of upper } \\
\text { layer seeds }(\%)\end{array}$ \\
\hline Changium smyrnioides & $\bar{X}$ & 4.13 & 2.41 & $<0.0001$ \\
Anthriscus sylvestris & $S$ & 0.03 & 0.055 & $<0.0001$ \\
\hline
\end{tabular}

表 2 各种储藏条件下明党参和峨参种子的萌发情况

Table 2 Seed germination of Changium smyrnioides and Anthriscus sylvestris under various storage conditions

\begin{tabular}{|c|c|c|c|c|c|c|c|}
\hline $\begin{array}{l}\text { 物种 } \\
\text { Species }\end{array}$ & $\begin{array}{c}\text { 温度处理 } \\
\text { Temperature } \\
\text { treatment }\end{array}$ & $\begin{array}{c}\text { 水分处理 } \\
\text { Water } \\
\text { treatment }\end{array}$ & $\begin{array}{c}\text { 萌发条件 } \\
\text { Germination } \\
\text { condition }\end{array}$ & $\begin{array}{c}\text { 萌发率 } \\
\text { Germination } \\
\text { rate }(\%)\end{array}$ & $\begin{array}{c}\text { 萌发值 } \\
\text { Germination } \\
\text { value }\end{array}$ & $\begin{array}{c}\text { 萌发持续时间 } \\
\text { Germination } \\
\text { time (day) }\end{array}$ & $\begin{array}{c}\text { 萌发开始日期 } \\
\text { Date of germin- } \\
\text { ation starting }\end{array}$ \\
\hline \multicolumn{8}{|c|}{ C. smyrnioides } \\
\hline & \multirow[t]{3}{*}{$\begin{array}{c}\text { 自然温度 } \\
\text { Natural temperature }\end{array}$} & $\begin{array}{c}\text { 变湿 } \\
\text { Fluctuant moisture }\end{array}$ & $\begin{array}{c}\text { 变湿 } \\
\text { Fluctuant moisture }\end{array}$ & $64.75 \pm 10.11$ & $0.83 \pm 0.19$ & $69.75 \pm 9.40$ & 11.23 \\
\hline & & $\begin{array}{l}\text { 淹水 } \\
\text { Flooding }\end{array}$ & $\begin{array}{c}\text { 淹水 } \\
\text { Flooding }\end{array}$ & $9.75 \pm 4.11$ & $0.18 \pm 0.06$ & $53.75 \pm 15.15$ & \\
\hline & & $\begin{array}{l}\text { 干燥 } \\
\text { Dry }\end{array}$ & $\begin{array}{c}\text { 变湿 } \\
\text { Fluctuant moisture }\end{array}$ & 0 & 0 & 0 & - \\
\hline & \multirow[t]{2}{*}{$\begin{array}{c}\text { 低温 } \\
\text { Low temperature }\end{array}$} & $\begin{array}{l}\text { 干燥 } \\
\text { Dry }\end{array}$ & $\begin{array}{c}\text { 变湿 } \\
\text { Fluctuant moisture }\end{array}$ & $56.25 \pm 14.24$ & $4.07 \pm 1.92$ & $32.63 \pm 5.66$ & - \\
\hline & & $\begin{array}{c}\text { 变湿 } \\
\text { Fluctuant moisture }\end{array}$ & $\begin{array}{c}\text { 变湿 } \\
\text { Fluctuant moisture }\end{array}$ & $55.98 \pm 6.06$ & $7.30 \pm 4.43$ & $24.13 \pm 1.81$ & 9.1 \\
\hline & \multirow{2}{*}{$\begin{array}{c}\text { 自然温度 } \\
\text { Natural temperature }\end{array}$} & $\begin{array}{l}\text { 淹水 } \\
\text { Flooding }\end{array}$ & $\begin{array}{c}\text { 淹水 } \\
\text { Flooding }\end{array}$ & $1.25 \pm 1.89$ & $0.52 \pm 0.55$ & $21 \pm 20.34$ & 12.6 \\
\hline & & $\begin{array}{l}\text { 干燥 } \\
\text { Dry }\end{array}$ & $\begin{array}{c}\text { 变湿 } \\
\text { Fluctuant moisture }\end{array}$ & 0 & 0 & 0 & - \\
\hline & \multirow[t]{2}{*}{$\begin{array}{c}\text { 低温 } \\
\text { Low temperature }\end{array}$} & $\begin{array}{l}\text { 干燥 } \\
\text { Dry }\end{array}$ & $\begin{array}{c}\text { 变湿 } \\
\text { Fluctuant moisture }\end{array}$ & 0 & 0 & 0 & - \\
\hline & & $\begin{array}{c}\text { 变湿 } \\
\text { Fluctuant moisture }\end{array}$ & $\begin{array}{c}\text { 变湿 } \\
\text { Fluctuant moisture }\end{array}$ & $45.12 \pm 10.41$ & $1.45 \pm 0.92$ & $47.78 \pm 2.64$ & 7.2 \\
\hline
\end{tabular}



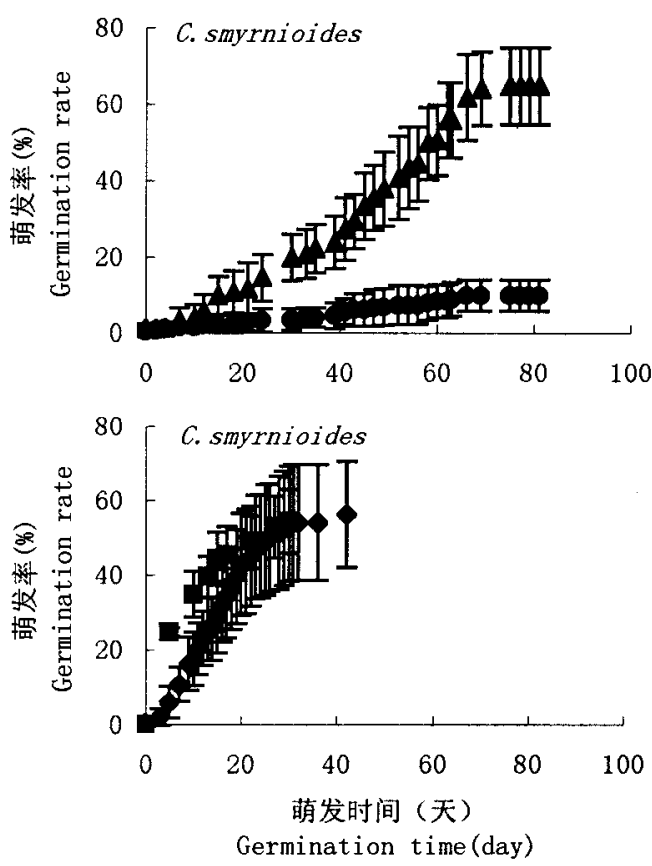

A 自然温度变湿

Natural temperature and fluctuant moisture

- 自然温度水淹

Natural temperature and flooding
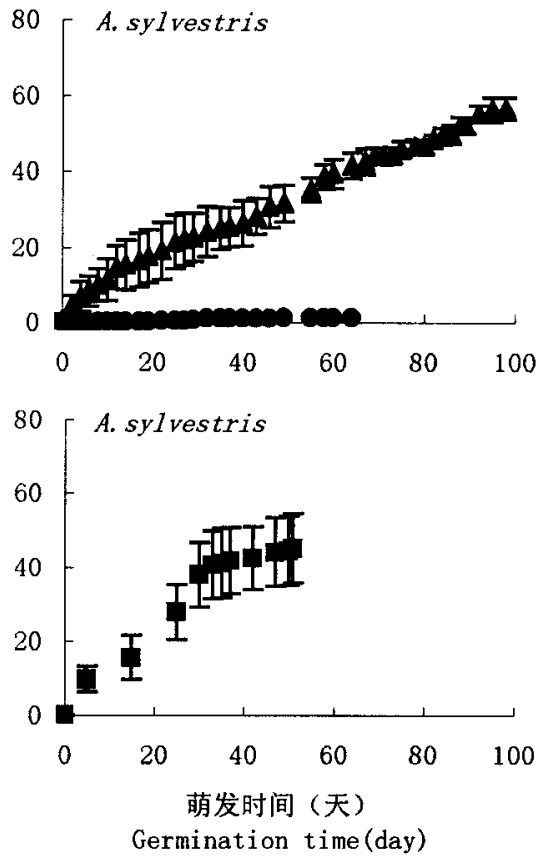

口 低温变湿

Low temperature and fluctuant moisture

- 低温干燥

Low temperature and dry

图 1 不同水分层积条件对种子萌发的影响

Fig. 1 Seed germination under various water conditions

进一步分析表明, 这两个种的种子萌发对水分响应 的共同点是:两种植物种子的萌发率均以经变湿层 积处理后 (沙含水量 1.7\% 21.4\%) 最高, 萌发持 续时间也最长;其次为淹水层积处理 (沙含水量为 $21.4 \%$ ); 而干燥层积处理 (沙含水量为 $1.7 \%$ ) 并且 自然温度咜藏则种子不萌发。两个种的不同之处在 于:在所有水分层积咜存条件下明党参种子的萌发 率均高于峨参, 明党参种子的耐淹水能力也略高于 峨参一一淹水层积处理的明党参、峨参种子萌发率 分别比变湿层积处理降低了 $84.9 \%$ 和 $97.8 \%$ (图 1 )。在变湿条件下，明党参萌发持续时间 (70 天) 较 峨参 (94 天) 短, 而淹水处理明党参萌发持续的时间 ( 54 天) 则较峨参 ( 21 天) 长。明党参萌发值较峨参 小很多, 分别为 0.18 和 0.52 。南高峰和午潮山 2 个种群中峨参的种子具有相近的萌发率, 变湿条件 下分别为 $56.5 \%$ 和 $58.0 \%$ 。

\section{3 不同温度层积处理对种子萌发的影响}

为研究温度对种子休眠解除和萌发的影响, 将 埋在干沙和湿沙中的种子分别放置在不同温度条件 (自然温度, $10^{\circ} \mathrm{C}$ 恒温)下进行层积处理 (表 2 )。结 果是, 在同样的干燥层积条件下, 低温䇄藏的明党参
种子能够萌发, 而峨参种子则不萌发; 干燥层积自然 温度咜藏的两个种都不能萌发。低温变湿咜藏的明 党参种子萌发率与自然温度变湿条件下相比差异不 显著 $(P=0.09)$, 而峨参的萌发率却比在自然温度 下低 $25.2 \%(P<0.04)$, 但萌发速率却提高了 1 倍 多。

两个种在低温变湿条件下咜存的种子萌发时间 均大大早于自然温度变湿处理的种子, 其中峨参在 7 月 20 日左右 (处理后 15 天) ,明党参在 9 月初(处 理后 40 天) 就开始萌发,此时自然温度为 32 $38^{\circ} \mathrm{C}$ 。将这两个种的低温下已经开始萌发的种子移 至自然温度下时, 萌发停止, 并且峨参在低温条件下 萌发的幼苗栽至自然温度下不能存活。

\section{4 种子萌发率对种群繁衍的影响}

野外两个种的种子落在地被层上，不定期地遭 到雨淋，因而自然温度变湿层积处理最接近自然状 态,可以反映出排除取食影响的萌发情况。变湿条 件下, 明党参和峨参下层种子的萌发率分别达到了 $64.8 \%$ 和 $56.5 \%$ （表 2 ），但明党参上层种子所占比 例将近 $1 / 3$, 较峨参高 6 倍多 (表 1 )。由于大多数植 物上层种子质量较差、萌发率较低( Lloyd, 1987; 
表 3 单株和群落种子的生产和萌发情况

Table 3 Production and germination of the individuals and community

\begin{tabular}{|c|c|c|c|c|c|c|}
\hline \multirow{2}{*}{$\begin{array}{c}\text { 物种 } \\
\text { Species }\end{array}$} & \multirow{2}{*}{$\begin{array}{c}\text { 储藏条件 } \\
\text { Storage } \\
\text { condition }\end{array}$} & \multicolumn{2}{|c|}{ 种子数 Number of seeds } & \multirow{2}{*}{$\begin{array}{c}\text { 萌发率 * } \\
\text { Germination } \\
\text { rate (\%) }\end{array}$} & \multicolumn{2}{|c|}{ 幼苗数 Number of seedlings } \\
\hline & & $\begin{array}{c}\text { 单株 Individual } \\
\text { ( Number/Individual) }\end{array}$ & $\begin{array}{l}\text { 群落 Community } \\
\left(\text { Number } / \mathrm{m}^{2}\right)\end{array}$ & & $\begin{array}{c}\text { 单株 Individual } \\
\text { ( Number/Individual) }\end{array}$ & $\begin{array}{l}\text { 群落 Community } \\
\left(\text { Number } / \mathrm{m}^{2}\right)\end{array}$ \\
\hline \multirow{2}{*}{ Changium smyrnioides } & NFT & \multirow{2}{*}{$163.36 \pm 134.88$} & \multirow{2}{*}{$320.67 \pm 113.06$} & $51.13 \pm 6.47$ & $83.52 \pm 61.07$ & $163.96 \pm 53.18$ \\
\hline & NF & & & $7.02 \pm 3.02$ & $11.46 \pm 9.04$ & $22.51 \pm 7.78$ \\
\hline \multirow{2}{*}{ Anthriscus sylvestris } & NFT & \multirow{2}{*}{$1351.22 \pm 995.88$} & \multirow{2}{*}{$13056 \pm 6982.70$} & $54.67 \pm 2.71$ & $738.71 \pm 553.45$ & $7137.71 \pm 3786.14$ \\
\hline & $\mathrm{NF}$ & & & $1.48 \pm 1.85$ & $19.99 \pm 12.18$ & $193.22 \pm 85.56$ \\
\hline
\end{tabular}

*假设上层种子不萌发的萌发率 Ignoring the germination rate of upper-layer seeds

$\mathrm{NFM}$ :自然温度变湿 Natural temperature and fluctuant moisture ; NF : 自然温度淹水 Natural temperature and flooding

Tripathi \& Khan , 1990 ;葛漟等,1998) ,所以在模拟 自然种群种子萌发率时必须考虑上层种子的萌发 率。根据 2001 年冬 2002 年春的萌发试验结果, 上层种子的萌发率为 $21.9 \%$,据此可推算出明党参 全部种子萌发率为 $51.1 \%$,略低于峨参 ( $54.7 \%)$ 。

\section{3 讨论与结论}

Vazquez-Yanes \& Orozco（1984）把热带湿润森 林种子的萌发分为两类:一类是迅速萌发，一类是延 迟萌发或被迫休眠，后者主要是先锋种、适应林窗的 物种和硬种皮的种子等。本研究中这两个种在接近 自然环境的变湿条件下，从母体下落后都不能立即 萌发, 而是需要至少 4 个月的休眠, 萌发过程可持续 1 个月以上,比亚热带的一些物种萌发慢 (陈章和 等, 1995)。常温财存的明党参种子要到冬季才能 萌发，因而对于明党参来说，低温是启动萌发的因子 之一。低温变湿层积萌发最早, 也需要 40 天的时 间，这表明该种种子需要一定时间的后熟作用才能 萌发。邱英雄和傅承新 (2001) 从种子解剖上发现 明党参种子脱离母体时胚还未成熟, 这与本实验结 果一致。

在本研究中, 低温变湿处理种子萌发时间远早 于自然温度变湿层积处理,这意味着低温是打破休 眠的条件之一。野外调查发现, 明党参分布生境为 常绿树带中的落叶树斑块, 并且种子萌发时间正好 是亚热带落叶树种落叶之后, 因此它是适应林窗 (这种林窗是一种时间性的光照林窗) 而萌发延迟 的物种。王中否和刘兴剑 ( 2000 ) 以及邱英雄和傅 承新 (2001) 对明党参群落的研究也证实了这点。 峨参生长在林缘路边、落叶阔叶混交林林下和水沟 边，经过休眠的较迟萌发可以防止幼苗被夏季的洪 水冲走, 这也是一种适应。明党参和峨参的幼苗可 以充分利用从 12 月份至翌年 $3 、 4$ 月份这一段时间
充足的光照来生长建成。Aoba (1967) 在调查了 27 个种的最适萌发温度后将植物种子的萌发分成 4 种 类型: 需要较温暖的条件萌发、需要较凉爽的温度才 萌发、在 $0^{\circ} \mathrm{C}$ 附近萌发、在很广的温度范围内萌发。 本研究的这两个种都在较凉爽温度条件至 $0^{\circ} \mathrm{C}$ 左右 萌发。这两种植物就是通过这种方式来调节种子后 熟的速率和萌发开始的时间, 使种子在萌发之前有 充足的时间来调节萌发地点和萌发季节, 使之更适 于萌发和幼苗的成活。

明党参、峨参的单株种子量存在着很大的差异， 峨参的单株种子数 (1350 粒) 是明党参 (163 粒) 的 8 倍, 单丛 (约 $2 \sim 9$ 株密生) 种子数达 3917 粒, $1 \mathrm{~m}^{2}$ 的样方内种子数是明党参的 41 倍。所以尽管两个 种的萌发率差别不大, 但种子数量的巨大差异已决 定了幼苗数量的差异。这样一来峨参单株产生的种 子苗数量约 9 倍于明党参, 单位土地面积上的密度 是明党参的 43.5 倍, 说明峨参种群更新能力远远大 于明党参, 受到强度干扰后有很强的恢复能力。

在淹水条件下,明党参和峨参种子萌发率明显 低于变湿条件, 说明长期淹水对种子活力构成一定 威胁。邱英雄和傅承新 (2001) 认为明党参种子成 熟时的梅雨造成其胚腐烂而死亡，从而降低了其萌 发率, 是导致该种濒危的一个重要原因。但本研究 结果不支持这个看法:虽然明党参种子长期处于水 分饱和状态下确实降低了萌发率, 但在这种情况下 每个母株每年也会新产生 11 株种子苗, $1 \mathrm{~m}^{2}$ 的样 方内每年可产生约 21 株新个体 (不考虑动物取食 等干扰因素)。对于明党参这样一生多次生殖的植 物来说, 种子繁殖出来的新个体数量应足够维持种 群繁衍, 因而这样的种子性状不至于造成其濒危。 事实上,如此高湿的环境对于野外明党参种子来说 也十分少见。并且野外调查还发现, 梅雨季节虽然 正是明党参种子下落的时期, 但种子并非都落在地 
上, 一直到梅雨季节结束, 仍有种子存留在母株上。 因此, 虽然梅雨季节的长期多雨会对种子的萌发造 成一定的影响，但种子的数量和质量不是导致明党 参濒危的直接原因。

明党参种子的千粒重虽然显著大于峨参,但种 子数量却少于峨参, 说明明党参对单个种子的投入 大。一般说来，种子越大种子萌发率越高，同时对幼 苗的存活越有利（Lloyd，1987 ,Tripthi ,1990），这意味 着明党参采取高千粒重、低生育率的 $K$-对策。一般 来说, $K$-对策的物种往往幼苗数量较少, 这样的种群 在受到强烈干扰时，难以在短期内恢复种群规模，容 易濒危。

与大多数植物相比, 峨参种子的萌发率并不低， 同时该种具有较高的种子数量,意味着峨参采取的 是低千粒重、高生育率的 $r$-对策 (Lloyd , 1987; Vaughton \& Ramsey ,1998)。这样的种群在受到干 扰时容易以在短期内恢复种群规模, 不容易濒危。

明党参在低温条件下经干燥和变湿处理后的萌 发速率都高于室温条件, 峨参种子则仅能在湿润条 件下咜存才可以保持活力, 而在低温湿润条件下萌 发过早。因此在保护栽培明党参时,可以采用低温 方式来保存种子，对峨参种子则可采用常温湿润方 式保存。

\section{参考文献}

陈章和, 陈惠琴, 刘惠琼, 郭丽荣, 文和群, 1995. 南亚热带常 绿阔叶林几个树种的种子萌发和幼苗发育. 植物学报, $37(8): 630 \sim 635$

葛湢, 常杰, 岳春雷, 陆大根, 1998. 杭州石荠苧种子萌发的 生理生态学研究. 植物生态学报, 22(2)：171 177

国家环保局, 中国科学院植物研究所, 1991。稀有濒危植物
的保护和研究. 北京: 环境科学出版社, $187 \sim 188$

刘守炉, 叶锦生, 1991. 中国明党参属植物综合研究. 植物研 究, 11(2) : 75 83

卢毅军, 葛漟, 常杰, 关保华, 岳春雷, 2001。杭州石荠苧不同 地方种群分化及空间利用策略研究. 生物多样性, 9 (3) : $254 \sim 259$

邱英雄, 傅承新, 2001. 明党参的濒危机制及其保护对策的 研究. 生物多样性, 9(2)：151 156

王中磊, 刘兴剑, 2000. 紫金山含明党参早春草本层的群落 学分析. 植物资源与环境学报, 9(2): $30 \sim 33$

Aoba T, 1967. Effects of different temperatures on seed germination of garden ornamentals in Allium. Journal of the Japanese Society for Horticultural Science, 36: $333 \sim 338$

Czabator F J, 1962. Germination value: an index combining speed and compliteness of pine seed germination. Forest Science, 8: $386 \sim 396$

Ge Y and J Chang, 2001. Existence analysis of populations of Mosla hangchowensis, an endangered plant. Botanical Bulletin of Academia Sinica, 42(4): $141 \sim 147$

Kainer K A, M L Duryea, M M Malavasi, E R Silva and J Harrison, 1999. Moist storage of Brazil nut seeds for improved germination and nursery management. Forest Ecology and Management, 116(1) : $207 \sim 217$

Lloyd D G, 1987. Selection of offspring size at independence and other size-versus-number strategies. American Naturalist, 129: $800 \sim 817$

Tripathi R S and M L Khan, 1990. Effect of seed weight and microsite characteristic on germination and seedling fitness in two species of Quercus in a subtropical wet hill forest. Oikos, 57: $289 \sim 296$

Vaughton G and M Ramsey, 1998. Sources and consequences of seed mass variation in Banksis marginata (Proteaceae). Journal of Ecology, 86: $563 \sim 573$

Vazquez-Yanes C and S A Orozco, 1984. Ecophysiology of germination in the tropical humid forests of the world: a review. In: E Medina, H A Mooney and C Mazquez-Yaness (eds.), Physiological Ecology of Plants in Wet Tropics. Dr W Junk Publishers, The Hague, Netherlands

(责任审稿人 :朱诚；责任编辑：时意专) 